\title{
Multiple haploids, triploids, and tetraploids found in modern-day "living fossil" Ginkgo biloba
}

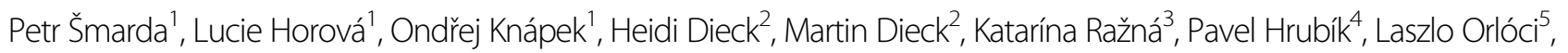
Laszlo Papp ${ }^{5}$, Kristýna Veselá', Pavel Veselý ${ }^{1}$ and Petr Bureš ${ }^{1}$

\begin{abstract}
Ginkgo biloba, the last extant representative of a lineage of Mesozoic gymnosperms, is one of the few seed plants with an exceptionally long ( 300 Myr) evolutionary history free of genome-wide duplications (polyploidy). Despite this genome conservatism, we have recently found a viable spontaneous tetraploid Ginkgo sapling during routine screening of several plants, demonstrating that natural polyploidy is possible in Ginkgo. Here we provide a much wider flow cytometry survey of ploidy in some European Ginkgo collections, and own seedlings (>2200 individuals and 200 cultivars). We found a surprisingly high level of ploidy variation in modern-day Ginkgo and documented altogether 13 haploid, 3 triploid, and 10 tetraploid Ginkgo plants or cultivars, most of them being morphologically distinct from common diploids. Haploids frequently produced polyploid (dihaploid) buds or branches. Tetraploids showed some genome size variation. The surveyed plants provide a unique resource for future Ginkgo research and breeding, and they might be used to accelerate the modern diversification of this nearly extinct plant lineage.
\end{abstract}

\section{Introduction}

Ginkgo biloba L. is the last representative of Ginkgoales, a group of gymnosperms that was an important component of "temperate" forest in the Mesozoic ${ }^{1,2}$. Ginkgoales's diversity has dramatically declined during the Cenozoic. Nevertheless, Ginkgo was still spread throughout the northern hemisphere in the Neogene ${ }^{3-5}$. Its distribution, however, was dramatically reduced during the Quaternary and the most recent ice ages, and only a few populations survived in isolated locations in China ${ }^{5,6}$. Though these locations are considered natural refugia, Ginkgo survival was also undoubtedly supported by its widespread planting by Buddhistic monks ${ }^{5}$. The phylogenetic uniqueness, the ancient nature, and the persistent

\footnotetext{
Correspondence: Petr Šmarda (smardap@sci.muni.cz)

1Department of Botany and Zoology, Masaryk University, Koltlářská 2, CZ-61137 Brno, Czech Republic

${ }^{2}$ Herrenkamper Gärten, Herrenkamp 1, DE-27254 Siedenburg, Germany

Full list of author information is available at the end of the article.
}

morphological resemblance of Ginkgo biloba to its fossil relatives lead people to call it a "living fossil".

Ginkgo trees were first introduced from China to Europe around the middle of the eighteenth century ${ }^{5}$. It was initially spread as a curiosity to botanical gardens, but its excellent prosperity in urban environments, its indisputable beauty, and its medicinal value have caused its cultivation and popularity to increase dramatically in recent decades. Today, Ginkgo fans are found worldwide planting this "living fossil" from sampled seeds. Gardeners have produced over 200 cultivars, most of them originating in the last three decades ${ }^{4,7,8}$.

This massive artificial planting and selection maintain peculiar genetic variants of Ginkgo that would otherwise have limited chances to establish in the wild. One of the most important mutations is polyploidy, i.e., wholegenome duplication ${ }^{9-11}$. Polyploidy has occurred quite frequently during the evolution of angiosperms, where it likely assisted in their massive Cenozoic diversification and their dominance of present-day vegetation ${ }^{12-15}$. In

\section{(c) The Author(s) 2018}

(c) (i) Open Access This article is licensed under a Creative Commons Attribution 4.0 International License, which permits use, sharing, adaptation, distribution and reproduction c. in any medium or format, as long as you give appropriate credit to the original author(s) and the source, provide a link to the Creative Commons license, and indicate if changes were made. The images or other third party material in this article are included in the article's Creative Commons license, unless indicated otherwise in a credit line to the material. If material is not included in the article's Creative Commons license and your intended use is not permitted by statutory regulation or exceeds the permitted use, you will need to obtain permission directly from the copyright holder. To view a copy of this license, visit http://creativecommons.org/licenses/by/4.0/. 
gymnosperms, however, polyploidy is rare ${ }^{16-20}$. Moreover, Ginkgo is among the few lineages of gymnosperms (and seed plants as a whole) with exceptionally long evolutionary histories free of whole-genome duplication $^{21}$. The last known duplication occurred in the common ancestor of Ginkgo and cycads about $300 \mathrm{Mya}^{22}$. Polyploid or haploid Ginkgo tissue cultures have already been obtained in vitro ${ }^{23,24}$, though plant regenerants were never successfully established, and other methods for polyploidy induction also seem ineffective in Ginkgo ${ }^{25}$. Despite this, we recently found a viable spontaneous tetraploid Ginkgo sapling in the Botanical Garden of Masaryk University in Brno, Czech Republic (Table 1) during routine genome size screening of some plants grown from the seeds of three females cultivated in this $\operatorname{garden}^{26}$. This finding demonstrated that natural polyploidy exists in Ginkgo, and we suggested ${ }^{26}$ that screening other existing Ginkgo collections may be an effective way of searching for other Ginkgo plants with unusual ploidies. These may eventually be used as mating partners for our tetraploid, for other breeding purposes, and for further experimentation.

In this paper, we describe the screening of ploidy variation in Ginkgo seedlings, cultivated trees, and available cultivars, including in total over 2200 Ginkgo individuals and 200 Ginkgo cultivars. In addition to exact ploidy detection and genome size estimations using flow cytometry, we also investigated the possibility of ploidy identification by measurement of stomatal guard cells and pores.

\section{Material and methods Material}

Several different sources (i-v) of Ginkgo plants were used for measurements of ploidy level in our study. The largest part represented (i) seedlings grown from seeds of maternal trees of the known tetraploid sapling found in the Botanical Garden of Masaryk University in Brno, Czech Republic (BG Brno). Ripened Ginkgo seeds fallen from all four diploid female trees were continuously collected for this experiment in autumn 2015. To remove fleshy outer seed coat, seeds were placed in a porous plastic garden crate immersed in water and mashed by hand; washed seeds were then surface-sterilized for a few minutes in a weak solution of sodium hypochlorite, rinsed in water, and maintained under room conditions for 1 day to dry their surfaces. The cleaned seeds were placed into wet vermiculite and stored in plastic zip-bags in a dark refrigerator at $\sim 4{ }^{\circ} \mathrm{C}$ until seeding time. Some seeds were also kept to ferment and were stored in natural outside conditions over the winter (experiencing multiple frost periods). Fleshy outer seed coat was removed from these seeds in the same way several days before the seeding. Altogether, 3570 seeds were sown at the beginning of
April 2016 in seedling trays ( $45 \mathrm{ml}$ per chamber) in a sand: chernozem:garden-compost substrate mixed at a ratio of $1: 2: 2$. Seedling trays were placed in the outside experimental garden and occasionally watered. Of the 3570 seeded Ginkgo seeds, 1360 emerged, producing in total 1533 individual seedlings. The extra seedlings came from 163 seeds that produced two seedlings and 5 seeds that produced three; i.e., 168 (12.8\%) emerging seeds were polyembryonic. Seeds stored in the refrigerator before sowing showed slightly higher emergence $(42.5 \%)$ than naturally stored seeds (35\%). Throughout 2016, leaves from all seedlings that emerged were collected for flow cytometry measurements. No new seedlings emerged in 2017.

Further, ploidy was determined also (ii) in seedlings and young saplings produced from seeds of local Ginkgo trees by Czech Ginkgo fans and growers (Table S1), (iii) in various other trees sampled opportunistically by ourselves or sent to us for analysis by various Ginkgo fans (Table S1), and (iv) in deep-frozen leaves from 79 Ginkgo trees cultivated across Slovakia which were sampled for other genetic analyses ${ }^{27}$ (Table S2). Ploidy screening also included (v) various Ginkgo cultivar collections and assortment of local Ginkgo sellers (Table S3). Altogether, 371 plants of about 200 cultivars were analyzed for ploidy level in our survey (Table S3).

\section{Ploidy and genome size}

Measurements of ploidy level and genome size were done using flow cytometry. The ploidy measurements were conducted using a Cy Flow ML (Partec, Germany) flow cytometer, AT-specific 4',6-diamidino-2-phenylindole (DAPI), and an external standard. To test for possible aneuploidy or intraploidy differences in genome size, the DAPI measurements were repeated with fresh green leaves from plants with unusual ploidies using additionally the internal standards Pisum sativum ${ }^{28}$ or Vicia faba ${ }^{28}\left(2 \mathrm{C}=7841\right.$ and 23,273 Mbp, respectively $\left.{ }^{29}\right)$. These measurements provided information about the relative genome size (Table S4). In selected plants, we also measured directly the absolute genome size (somatic nuclear DNA content) using the same internal standards and intercalating propidium iodide (PI) dye.

The preparation of samples followed Otto $^{30}$ and was similar for all flow cytometry measurements. A piece of leaf was chopped using a sharp razor blade (in the case of internal standardization, it was chopped together with the leaf of the standard) in a Petri dish containing $0.5 \mathrm{ml}$ of Otto I buffer $(0.1 \mathrm{M}$ citric acid, $0.5 \%$ Tween 20). To improve the signal/background ratio, the original Otto I solution was mixed 1:1 with $0.1 \mathrm{M}$ hydrochloric acid and supplied with additional Tween 20 (4.4\% final concentration). An additional $0.5 \mathrm{ml}$ of "improved" Otto I buffer was added. The crude nuclear suspension was 
filtered through 50- $\mu \mathrm{m}$ nylon mesh. The filtered suspension was finally supplemented with $1 \mathrm{ml}$ of Otto II buffer (0.4 $\left.\mathrm{M} \mathrm{Na}_{2} \mathrm{HPO}_{4} \cdot 12 \mathrm{H}_{2} \mathrm{O}\right)$ supplemented with either DAPI (final concentration $2.0 \mu \mathrm{g} / \mathrm{ml}$ ) or PI (final concentration $50 \mu \mathrm{g} / \mathrm{ml}$ ), depending on the type of the measurement. Using DAPI dye and the above procedure, we obtained DNA signal and were able to detect ploidy even in (i) yellow, fallen; (ii) 1-year-old, deep-frozen; and (iii) fewdays-old, dried Ginkgo leaves. At least 1000 nuclei were analyzed for measurements of ploidy level and at least 5000 nuclei for measurements of relative or absolute genome size. Measurements of absolute genome size were repeated three times on different days per each sample and finally averaged.

\section{Stomatal parameters}

In addition to the exact flow cytometry measurements of ploidy and genome size, we further attempt to test alternative, less instrumental-dependent methods of ploidy detection. The easiest method perhaps is measurement of stomata, particularly their guard cells ${ }^{31,32}$. Because stomata are partly sunken in Ginkgo leaves, we observed their parameters (guard cell length, stomata width, stomata area, stomatal pore length, width, and area; Fig. 1) directly in epidermal peels. Peels were prepared by boiling about $1 \mathrm{~cm}^{2}$ of the central part of a fresh leaf in about $25 \mathrm{ml}$ of commercial household bleach (SAVO, Czech Republic; containing 1-5\% sodium hypochlorite and $0.5-2 \%$ sodium hydroxide) for about $10 \mathrm{~min}$, until the leaf became nearly transparent and both leaf sides were separated or nearly so. The bleached epidermal peels were washed in distilled water and mounted in glycerol. The peel of the abaxial, stomata-bearing leaf side was observed with a microscope (Olympus BX51) under $\times 200$ magnification. For each Ginkgo sample, measurements were done in several leaves (usually up to five) and for at least 50 stomata in total (Table S5).

\section{Results}

The screening in seedling/sapling collections revealed altogether two polyploid plants: a tetraploid seedling in the collection of Jana Blažíčková and a triploid sapling in the collection of Vladimír Ožana (Table 1, S1; Figs. 2 and 4). A 15-year-old spontaneous triploid tree was found in the personal garden of Ondřej Knápek (Fig. 4) and another 12-year-old spontaneous triploid (used as a rootstock) in a Ginkgo collection in Tordas, Hungary (Table 1, S1). The screening of various Ginkgo cultivar collections showed even much extensive ploidy variation. Of about 200 screened Ginkgo cultivars (Table S3), 13 were found to be haploid (Menhir, Obelisk, Fastigiata, Anny's Dwarf, Baldii, Chris' Dwarf, Clica, Munchkin, Barabit's Fastigiata, Chase Manhattan, Nory's, Rocky, Little Joe) and eight tetraploid (Adam, Bullwinkle, Curly
Leafs, Freak, Horizontalis, Hoss, Jagged Jade, Pendula Gruga) (Table 1, Figs. 2, 3a and 4). In the cases of cultivars Anny's Dwarf, Fastigiata, and Horizontalis, diploid individuals were also found (Table 1, S3).

Haploids or triploids showed no significant intraploidy genome size variation (Table S4). In tetraploids, however, genome size varied to some extent, and we observed a 1.04-fold difference between the cultivars with the largest contrast, Pendula Gruga and Jagged Jade (Table S4, Fig. 3b). The absolute genome sizes (somatic nuclear DNA contents) for selected plants/cultivars were as follows: "Obelisk" ( $2 \mathrm{C}=1 \mathrm{x}=10.16 \pm 0.13 \mathrm{Gbp})$, "Kristine" $(2 \mathrm{C}=2 \mathrm{x}=19.53 \pm 0.48 \mathrm{Gbp})$, "Knapek's Triploid" $(2 \mathrm{C}=$ $3 \mathrm{x}=29.19 \pm 0.30 \mathrm{Gbp})$, "Pendula Gruga" $(2 \mathrm{C}=4 x=$ $38.12 \pm 0.71 \mathrm{Gbp})$, "Bullwinkle" $(2 \mathrm{C}=4 x=38.71 \pm 0.56$ Gbp), and "Jagged Jade" ( $2 \mathrm{C}=4 x=39.41 \pm 0.55 \mathrm{Gbp})$.

Ginkgo haploids seem to be characterized by smaller leaves and dwarf or upright columnar growth (Fig. 2, Table 1), though not all small-leaved and/or dwarf or upright-growing cultivars examined were haploid. All three triploids were growing well and distinguished by relatively large and deeply bilobed leaves, which in diploids are usually found only in annual shoots. Tetraploids had, as their most distinguishing characteristics, a laciniate (irregularly jagged to finely irregularly multilobed) leaf margin (Fig. 2). Also, their leaves were large (with the exception of a young Blažícková's tetraploid and Freak), robust, and thick, and they often had wide and flattened petioles (Fig. 2).

In nine haploid cultivars (Anny's Dwarf, Baldii, Barabit's Fastigiata, Fastigiata, Chase Manhattan, Chris Dwarf, Little Joe, Menhir, Munchkin), we observed buds or whole isolated branches with apparently enlarged leaves (Fig. 5, Table 1, S3). Larger haploid plants often had several such buds or branches (Fig. 5). These enlarged leaves were usually diploid or sometimes formed with a mixture of haploid and diploid tissue (in Anny's Dwarf, Barabit's Fastigiata, Fastigiata, Little Joe). This indicates somatic mutation from haploid to diploid (i.e., dihaploidization) happens frequently in haploid cultivars.

Average stomatal guard cell lengths of haploids $(38.4-44.5 \mu \mathrm{m})$ and tetraploids $(61.4-71.6 \mu \mathrm{m})$ were always shorter or longer, respectively, than the average among diploids $(45.9-55.7 \mu \mathrm{m})$ (Fig. 6, Table S5). For haploids with largest stomata (Obelisk, Clica, and two samples of Chris Dwarf), however, guard cell lengths were not statistically different (Tukey HSD test, $p>0.05$ ) from some small-leaved diploids (Maribo, Troll). Average guard cell lengths of triploids $(53.3-64.9 \mu \mathrm{m})$ were intermediary between those of diploids and tetraploids and not clearly distinguishable from either of them $(p>0.05$; Fig. 6, Table S5). A similar pattern was observed also for measurements of stomatal width and stomatal area, thought their values overlap slightly more between the 


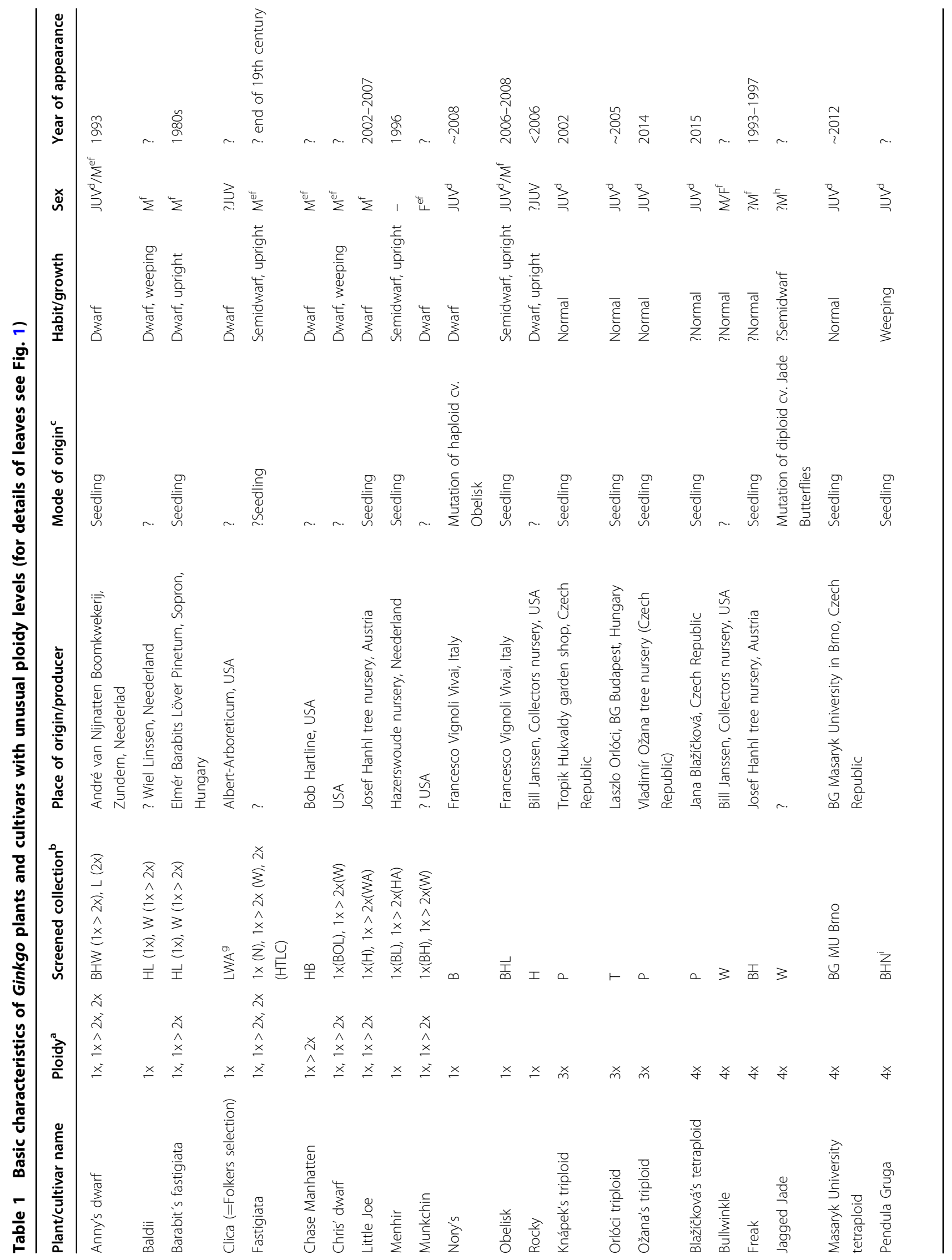




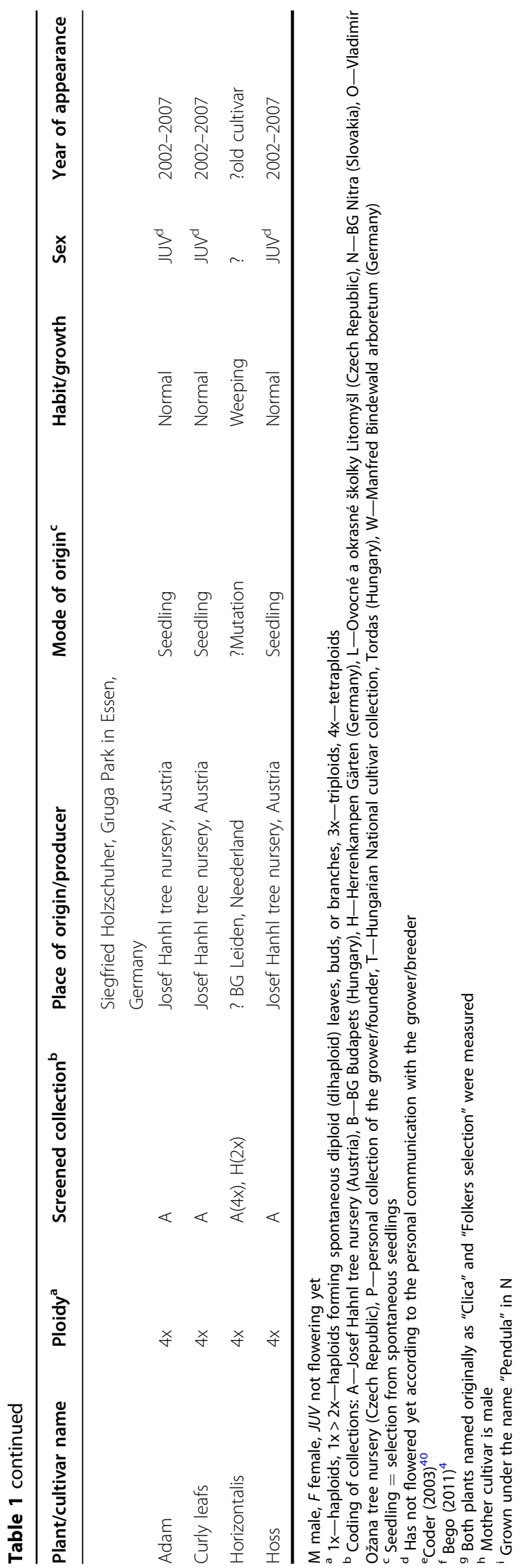

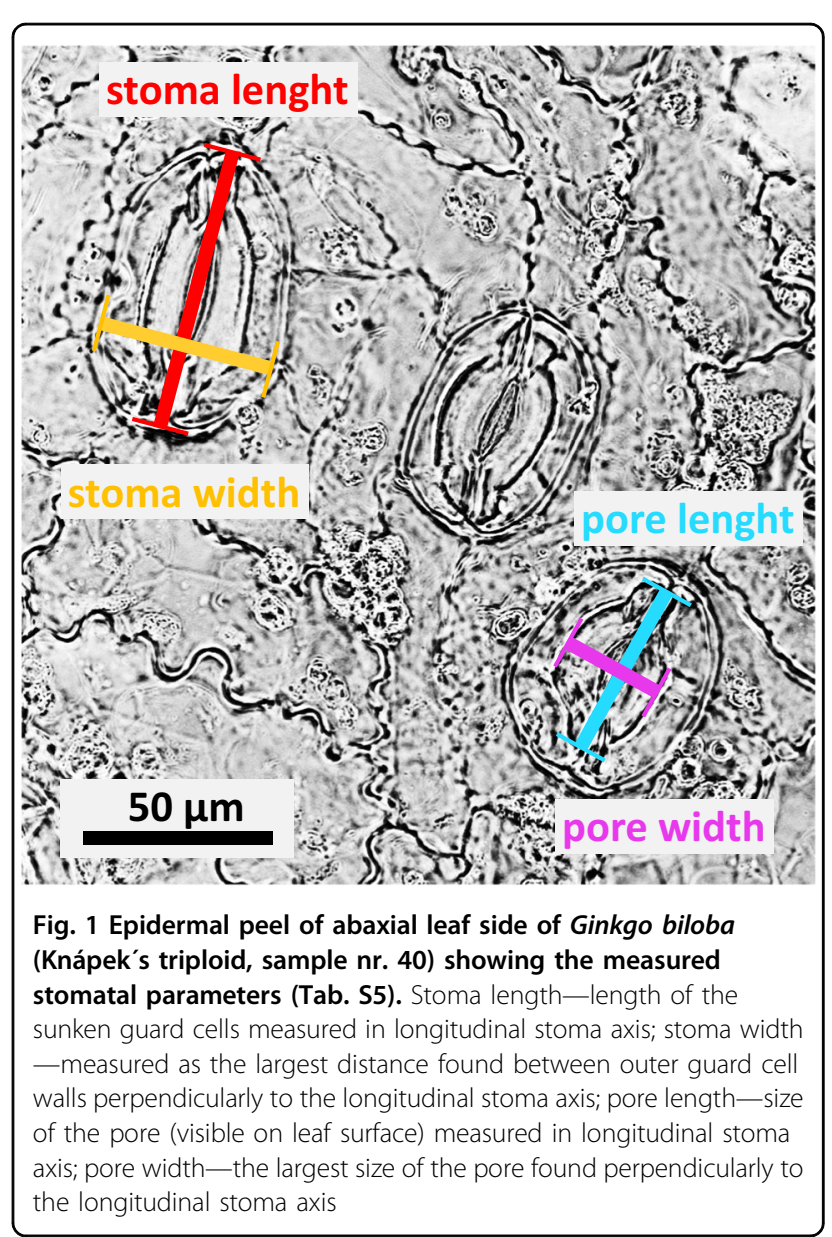

different ploidies than in the case of guard cell length (Fig. S1 and S2). Pore parameters were highly correlated with the respective parameters of stomata (Adjusted $R^{2}$ from linear regression of sample medians $=0.855,0.840$, 0.895 for length, width, and area, respectively; Fig. S3). However, the pore parameters frequently overlaps between different ploidies, particularly between haploids and dwarf Ginkgo diploids, and in general showed worse discrimination of haploid and polyploid Ginkgo plants (Figs. S4-S6) as compared to the guard cell length.

\section{Discussion}

Despite the exceptional polyploidy-free evolutionary history of Ginkgo ${ }^{21,22}$, our study clearly demonstrates Ginkgo is capable of spontaneous polyploidy and shows that the modern European or American cultivar assortment already includes multiple Ginkgo plants of unusual ploidies, including several haploids, triploids, and tetraploids. The majority of such plants are relatively young, having originated in the last $20-30$ years as a consequence of increased interest in Ginkgo and selection of plants with horticulturally attractive foliage or growth form. They are perhaps all of spontaneous origin. At least, 


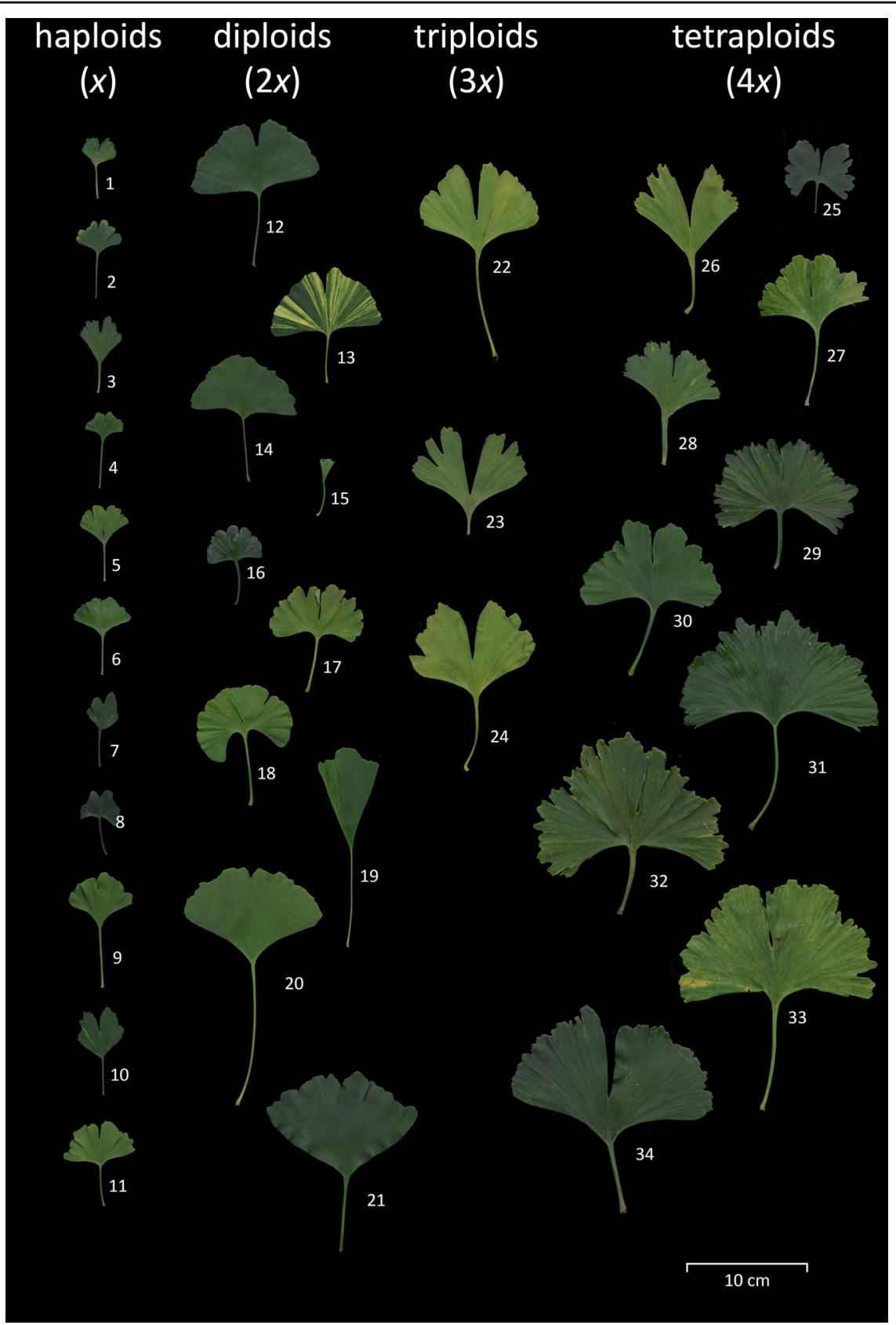

Fig. 2 Scanned mature leaves of some selected diploid and all detected haploid and polyploid Ginkgo plants and cultivars. Of particular interest are the smaller leaf size of haploids, the deep central groove (lobbing) in the leaves of triploids, and the large size and finely irregularly lobed/ jagged (laciniate) leaf margins in tetraploids. Scale bar $=10 \mathrm{~cm}$. Haploids: 1-Clica, 2-Rocky, 3-Fastigiata, 4-Baldii, 5-Little Joe, 6-Nory's, 7-Chris's Dwarf, 8-Munchkin, 9-Obelisk, 10-Menhir, 11-Anny's Dwarf. Diploids: 12-old tree BG Budapest, 13-Finger Variegated, 14-San José Gold, 15-Tubifolia, 16-Pine Glen Dwarf, 17-Mephisto, 18-Blenheim Arboretum, 19-Saratoga, 20—King of Donting, 21-Nelleke. Triploids: 22-Orlóci Triploid, 23-Ožana's Triploid, 24-Knápek's Triploid. Tetraploids: 25—Blažíčková's Tetraploid, 26—Masaryk University Tetraploid, 27-Freak, 28-Bullwinkle, 29-Jagged Jade, 30—Hoss, 31—Pendula Gruga, 32—Curlie Leafs, 33—Adam, 34—Horizontalis

we have no direct evidence (Table 1) that any originated by some more advanced breeding or polyploidy-inducing methods. The sowings of $>10,000$ seeds and consequent selection of morphologically attractive seedlings by Josef Hahnl in Austria in 1993-1997 and 2002-2007 yielded in total four tetraploid and one haploid cultivar. Together with the evidence from the other screened sowings, the frequency of appearance of unusual ploidies in seminatural, cultivation conditions may be one in every few thousand. It is therefore likely that other spontaneous 

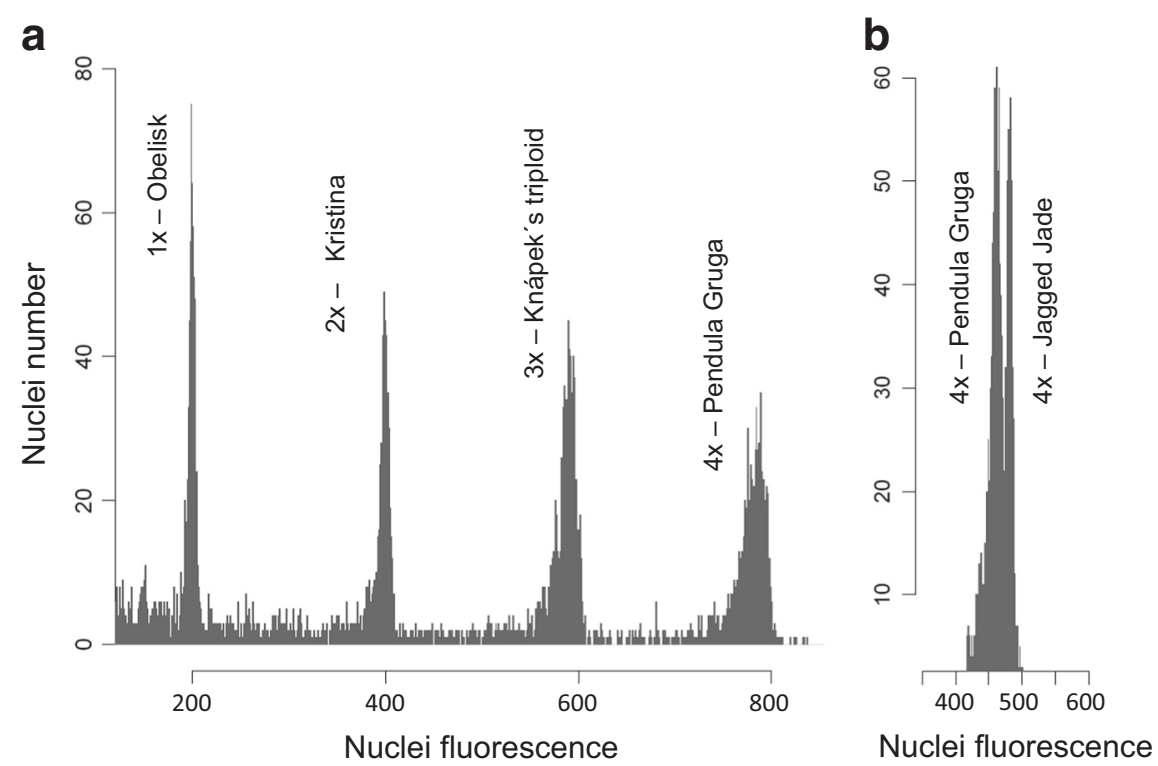

Fig. 3 Flow cytometry histograms showing difference in relative genome size among measured Ginkgo plants. a among plants of all detected ploidy levels, b between the two most genome-size-extreme tetraploid Ginkgo cultivars (peak ratio = 1.041)
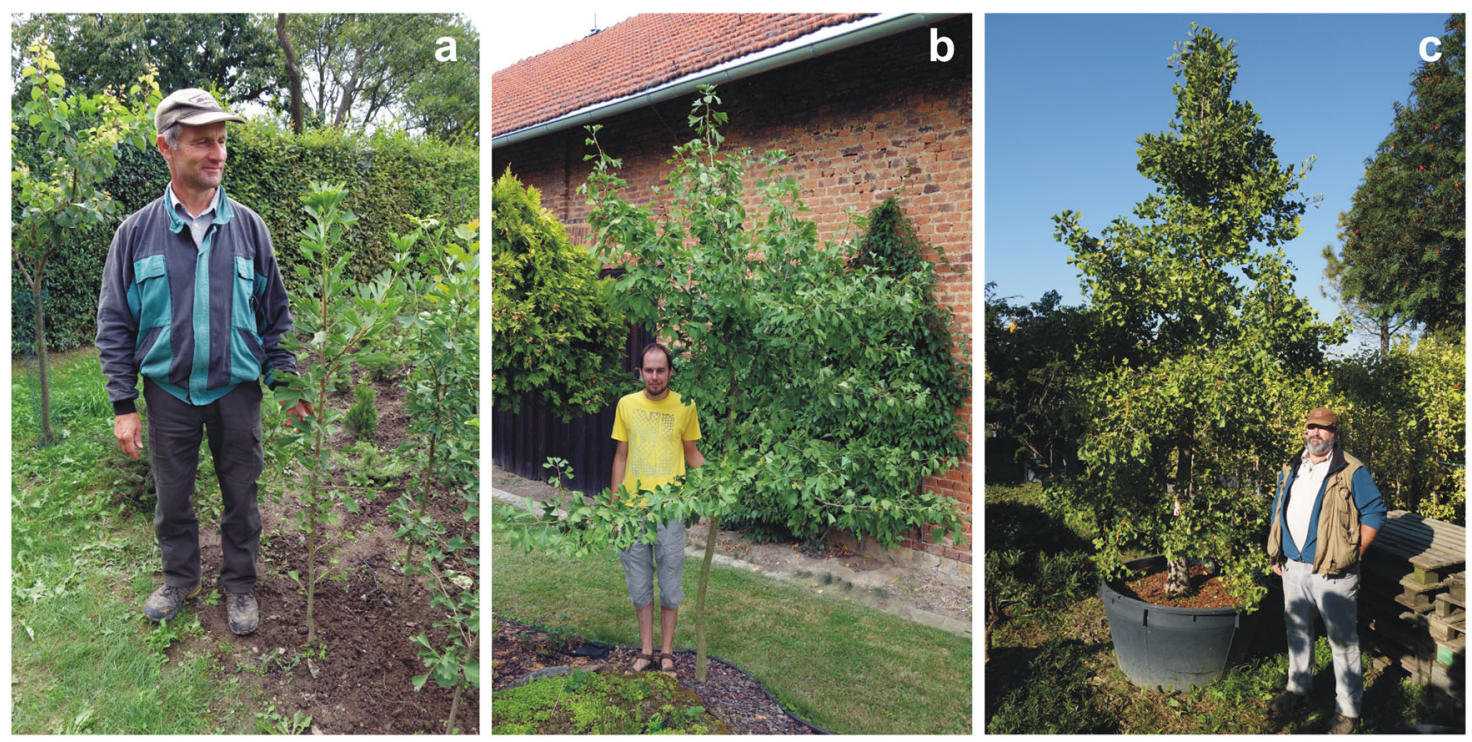

Fig. 4 Examples of polyploid Ginkgo plants and their growers. a Vladimír Ožana with his 3-year-old triploid sapling, b Ondřej Knápek with his 15year-old, pruned triploid tree, c Josef Hahnl with the potted, 22-year-old mother plant of his tetraploid cv. Freak

Ginkgo plants with unusual ploidies could be found by detailed screening of other Ginkgo nurseries or collections.

Ginkgo has naturally higher genetic diversity and a much longer tradition of cultivation in China and other Asian countries ${ }^{33}$, where it is mostly breed for fruit shape and seed production ${ }^{7,34}$. In Europe and America, however, the Ginkgo is cultivated and bred fast exclusively for decorative purposes, and fruiting plants are generally unwanted. The Asian Ginkgo collections may therefore provide different genetic types of haploid or polyploid Ginkgo plants, and ploidy screening in these Ginkgo collections is therefore worthwhile.

\section{Haploids}

Spontaneous haploids are known in many ordinarily diploid plant species, though in gymnosperms such haploids seem quite $\operatorname{rare}^{35-37}$. These haploids mostly 

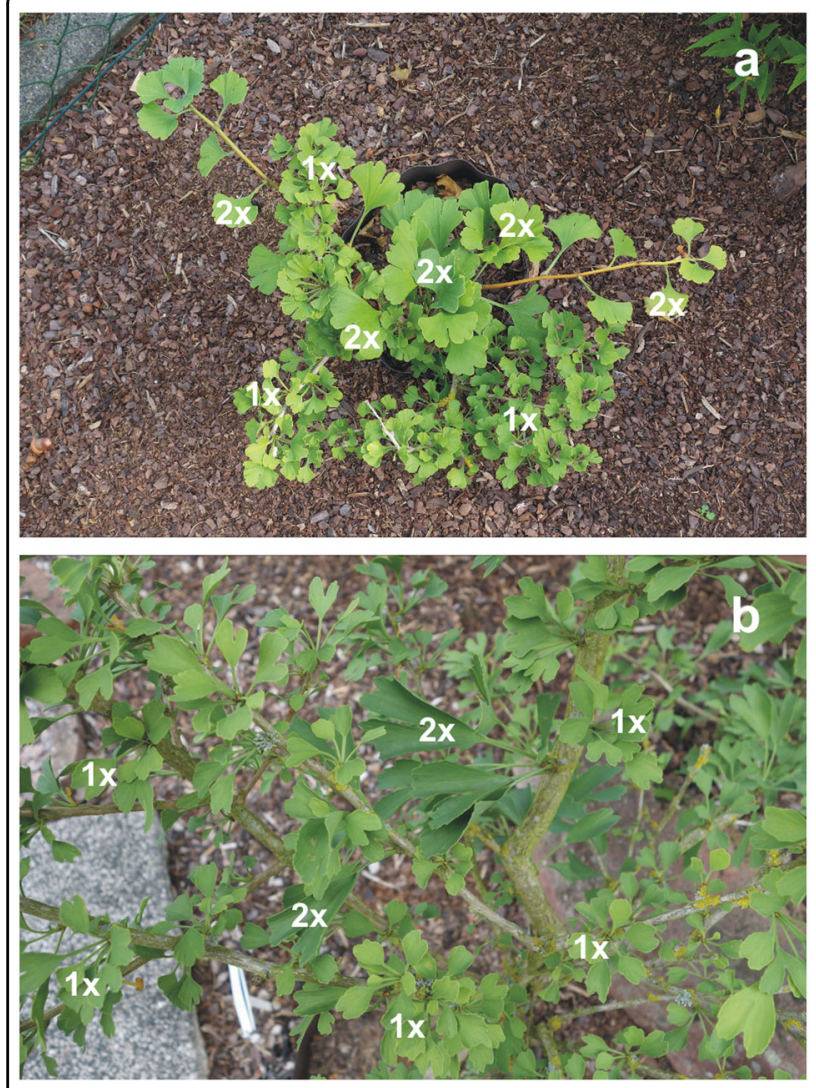

Fig. 5 Spontaneous polyploid (dihaploid) leaf buds or whole branches (2x) are frequently formed on haploid (1x) Ginkgo plants. a cv. Chase Manhattan, b cv. Anny's Dwarf; both from the personal Ginkgo garden of Manfred Bindewald (Germany) originate from a failure to fertilize an egg cell, which then continues in development as a haploid embryo ${ }^{36}$. Because Ginkgo females are heterogametic ${ }^{38,39}(\mathrm{ZW})$, this "gynogenic" pathway of haploid formation should produce an equal portion of male (Z) and female (W) haploids. However, available evidence indicates that the male sex prevails in haploids ${ }^{4,40}$ with the female sex reported only for cv. Munchkin (Table 1). Nevertheless, the notes of sex in Ginkgo haploids need to be taken with care, because haploids are usually sterile due to problems with meio$\mathrm{sis}^{41}$. Noting that (i) fertility of haploids is commonly restored by polyploidization ${ }^{42}$ (dihaploidization) and (ii) our observations of frequent formation of dihaploid buds or branches in haploids, it is not unlikely that some notes about formation of sexual organs in haploids may be related to their dihaploidized parts. Whereas dihaploidized male haploids would have the standard male chromosomal constitution (ZZ) and therefore should not have any problems with sex expression, the dihaploidy in haploid females will lead to the formation of curious superfemales (WW) whose viability remains uncertain. Whether this fact could be related to the prevalence of males in haploids remains an open question.

Haploidy in Ginkgo seems related to either dwarf bushy or upright columnar growth. The height of dwarf haploids usually does not exceed $3 \mathrm{~m}$. The upright-type haploids grow generally more vigorously, and their height is expected to reach $5 \mathrm{~m}$ in $\mathrm{cv}$. Menhir (US patent Nr. US PP24,226 P2). Even larger trees, up to $20 \mathrm{~m}$ height, are reported for haploid cv. Fastigiata ${ }^{8}$, a growth form already known at the end of nineteenth century ${ }^{7}$. However, the

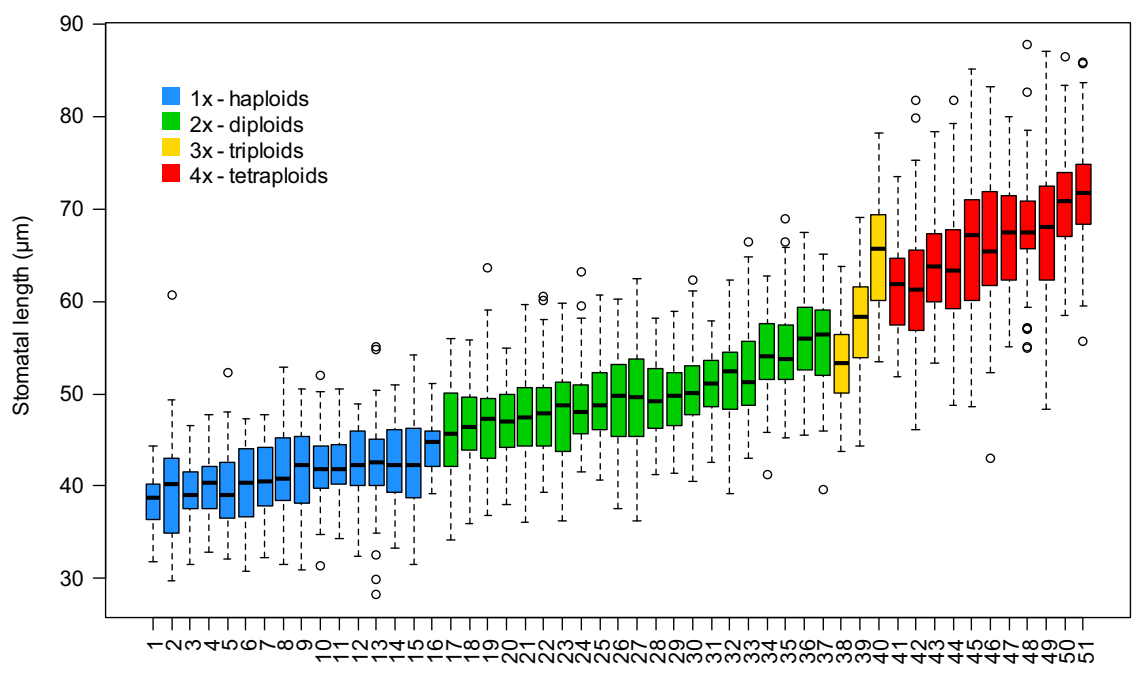

Fig. 6 Stomatal (guard cell) lengths of different Ginkgo samples (cultivars) showing positive correlation with ploidy level and documenting the possibility of using this technique to detect haploid and tetraploid Ginkgo plants. Boxplots show: median (thick horizontal line), interquartile range (box), non-outlying values range (whiskers), and outliers (circles). Haploid samples 10, 12-16 show statistical similarity with one or more diploid samples (Tukey HSD test, $p>0.05$ ); diploids always statistically differ from tetraploids; triploids cannot be distinguished in general from either diploids or tetraploids. Sample coding follows Table S5. For figures of other stomatal parameters see Figs. S1-S6 
name "fastigiata" is used quite freely to name upright growing trees of various origins, and reports of "fastigiata" trees may also relate to diploids (Table 1, S3). The two haploid trees of cv. Fastigiata we observed both reached $4.7 \mathrm{~m}$ (a 16-year-old tree in BG Nitra and a 9-year-old tree in the garden of M. Bindewald). It is to be noted, however, that available growth data in Ginkgo haploids and polyploids (Table 1) mostly originate from grafted plants, whose growth may also depend on the vitality of the used rootstock.

Dwarfism is a common feature of plant haploids ${ }^{37,43}$. These dwarf plants are naturally popular with home gardeners, and preferential selection of dwarf phenotypes in Ginkgo nurseries is with no doubt a reason for the relatively high frequency of haploids in the modern Ginkgo assortment. The high frequency of Ginkgo haploids might also relate to the frequent polyembryony of Ginkgo seeds ${ }^{44}$, reaching $12.8 \%$ in our sowing experiment (see Materials and methods). Polyembryonic seeds show an increased rate of haploid formation in many angiosperm species and were proved as a useful source of haploids also in some conifers ${ }^{37,45}$. At the moment, we lack information about whether the known Ginkgo haploids have originated from regular or polyembryonic seeds. Nevertheless, careful inspection of twin or triplet seedlings originating from polyembryonic seeds may be one of the promising ways of searching further Ginkgo haploids.

Dihaploid plants will lose a number of the characters of the haploid plants (such as dwarf growth and small leaf size, Fig. 5). Therefore, dihaploid branches are removed from dwarf Ginkgo haploids for esthetical reasons. This is paradoxical, because such dihaploidized parts may be especially useful in further Ginkgo breeding, considering that the production of dihaploids is a frequent target of modern, advanced crop breeding ${ }^{37,41,46}$. Among the most important features of dihaploids is complete homozygosity. This allows the expression of rare recessive genes, the fixation of certain characters and properties, and their efficient transmission to the progeny ${ }^{46}$. The reduced DNA sequence complexity of haploids and homozygous dihaploids may also facilitate genome sequencing and assemblage $e^{37,47,48}$. The current draft genome sequence of Ginkgo, for example, was obtained from female megagametophyte tissue ${ }^{49}$. That tissue is certainly less handy for routine DNA extraction than leaves.

\section{Polyploids}

Spontaneous triploid or tetraploid plants are found from time to time in many regularly diploid species and are also rarely reported among some gymnosperms ${ }^{17,18,50}$. Ginkgo may be now included to these rare examples, suggesting that spontaneous polyploidy is possible in plants irrespective of their eventual genome conservatism over geological timescales. Moreover, the number of reported polyploid Ginkgo plants indicates spontaneous polyploidy is certainly not extremely rare. The long polyploidy-free evolutionary history of Ginkgo therefore must be due to limited survival and post-emergence counter-selection of polyploid plants, such as, for example, due to decreased belowground or aboveground competitive performance, stress tolerance, lack of mating partners, or lowered fertility.

Spontaneous triploids originate mostly from fertilization by unreduced gametes or from inter-ploidy $\mathrm{crosses}^{51}$, the latter option being impossible at the moment due to the immaturity of all documented Ginkgo polyploids (see also below). Though triploids seem to appear in lower frequency in our survey compared to haploids or tetraploids, this is perhaps only due to a selection bias in the nurseries. Triploids are likely indistinguishable from diploid seedlings and saplings, so they remain mostly neglected during selection of unusual Ginkgo plants worthy of further cultivation and propagation (Figs. 2 and 4).

The spontaneous Ginkgo tetraploids cannot perhaps originate in any other way than as a somatic mutation (polyploidization) at some developmental stage. For tetraploids grown up from seedlings, this polyploidization must have happened during embryo formation or early during seedling emergence. In cultivars Pendula Gruga or Jagged Jade, both known to have originated as a branch sport (spontaneous bud mutation) on a likely diploid maternal tree (Table 1), polyploidy has happened perhaps analogously to the dihaploidy events observed in Ginkgo haploids. Polyploid gymnosperms have also been produced artificially by colchicine treatment in several species $^{18,52}$; however, we are not aware of any such successful attempts in Ginkgo.

The homogeneity of genome size in haploids and triploids indicates these are pure examples of whole-genome mutations. The variation in genome size found in tetraploids, however, indicates that polyploidy must be coupled here with aneuploidy or other kinds of DNA eliminations resulting in slight genome size reduction in some tetraploid cultivars compared to the ideally doubled genome size.

Spontaneous or artificial triploid or tetraploid gymnosperms are usually slow growing, sterile, and short lived ${ }^{17,18}$. There exist some older gymnosperm polyploids in Pinus, Larix, and Picea which have grown for many years and have eventually reached maturity ${ }^{52,53}$, but their slow growth and high sterility disfavored them from further breeding programs. Polyploidy as a whole is therefore considered as an unpromising path for gymnosperm tree breeding ${ }^{18,52,54}$. In contrast to this opinion, many Ginkgo triploids and tetraploids grow quite well (Fig. 4, Table 1). Knápek's 15-year-old triploid, for example, tolerates 
yearly pruning to reduce its height to a "garden acceptable" $3.5 \mathrm{~m}$, and Ožana's 3-year-old, $140 \mathrm{~cm}$ high triploid shows growth similar to its same-age diploid siblings cultivated under the same conditions in the nursery (Fig. 4). The 22 -year-old mother plant of cv. Freak reaches only about $3.5 \mathrm{~m}$. However, it is cultivated rather as a bonsai plant in a 3001 pot (Fig. 4), which substantially restricts its natural growth. The other seed-borne tetraploids in Josef Hahnl nursery grow as well as the diploids (all grafted on diploid rootstock) and the situation is similar with the Masaryk University tetraploid (ref. ${ }^{26}$ : Fig. 1a). Their vital growth and relatively large leaves may predestine some of these polyploids for commercial planting and leaf production for the pharmacological industry, especially if the polyploidy has any advantageous effect on the composition of pharmacologically important compounds. Conversely, synthetic preparation of Ginkgo polyploids may prove to be an effective way of breeding high leaf productive Ginkgo cultivars. These eventual breeding attempts may be highly accelerated if some of the existing triploid trees prove to be fertile. Triploids may produce gametes with variable ploidy levels ${ }^{51}$ (haploid, diploid, or unreduced triploid) and mating with such a triploid individual may therefore provide a large spectrum of polyploid plants for effective selection of desired properties.

Compared with the tetraploids originating from seeds, those originating from buds (Pendula Gruga, Jagged Jade) grow more slowly, which is consistent with observations from other polyploid tree gymnosperms (conifers). In addition to slow growth, the common characteristic of these Ginkgo plants and other conifer tetraploids is a tendency to pendulous or weeping growth, as documented, for example, in the old tetraploid tree of Larix decidua (ref. ${ }^{53}$ : Plate 1) or in tetraploid Pinus sylvestris (ref. ${ }^{52}$ : Fig. 1). These growth characteristics predestine these bud-originated Ginkgo tetraploids to be grown rather as curiosities in parks and personal gardens. However, the evolutionary potential of such plants as well as any other Ginkgo tetraploids should not be underestimated $^{17,18}$.

The rare notes about spontaneous formations of female, fruit-bearing branches on regularly male (homogametic gender) trees ${ }^{55}$, for example, indicate that any Ginkgo individual bears genes for both sexes, irrespective of sexual chromosome dimorphism. As in other dioecious plants, the sex determination in Ginkgo therefore must depend only on regulation of gene expression ${ }^{56-58}$. Polyploidy may easily break down any gene regulation ${ }^{59,60}$, and there are several examples of dioecious diploids forming hermaphrodite individuals or even separate hermaphrodite species following induced or natural polyploidy $^{61-64}$. We are thus looking forward to the first observation of the sexes of the Ginkgo tetraploids in our survey, which are all still quite young and immature. If one were to be a hermaphrodite able to produce viable seeds, it could be even considered to be a new Ginkgo species.

\section{Cell and stomatal size}

Genome size (and thus also polyploidy) determines minimum cell size. Therefore, genome size and ploidy usually correlate with the size of specific cells where smaller size provides some functional advantage ${ }^{65}$, such as the guard cells of stomata in plants ${ }^{29,31,32,66,67}$. The correlations with genome size and ploidy may also appear to a lesser extent with the size of whole organs, especially when formed with relatively constant cell numbers ${ }^{66,68-70}$. Ginkgo is no exception in this respect, and ploidy level correlates in Ginkgo positively with leaf and stomatal size. Leaves of Ginkgo haploids seem always smaller compared to leaves of any other Ginkgo, while those of triploids and tetraploids are regularly among the largest observed in the surveyed Ginkgo plants (Figs. 2 and 5). The leaves of Ginkgo tetraploids also seem thicker, as sometimes observed in other polyploid plants ${ }^{66,68}$, and somewhat crispy. Such characteristics are perhaps all a consequence of increased cell size inside the leaves. Even though leaf size may vary with branch or plant age, with leaf position on the tree, and with cultivation conditions, these leaf characteristics can serve as a first-step identification of plants with unusual ploidies or polyploidized buds and branches.

Like the size of leaves, guard cells of stomata are remarkably small in haploids and their size generally increases with increasing ploidy level. Because stomatal size is much conservative and less dependent on cultivation conditions ${ }^{71}$ compared to leaf size, its measurement can provide an even better alternative for ploidy identification in Ginkgo, at least for haploids and tetraploids. However, one must be careful to account for the partly sunken placement of Ginkgo stomata and to precisely estimate the guard cell edges in observed epidermal peels. Despite this methodical difficulty, we hope measurements of guard cells combined with leaf morphology can facilitate the discovery of other haploid and polyploid Ginkgo plants that may still remain hidden in various other Ginkgo nurseries and collections. Based on images on the Internet, for example, good candidates for further tetraploids seem to be cv. Crispin's Jaded Jester, cv. Medusa and for haploids cv. Gokusho-ba.

Stomatal sizes of Ginkgo triploids and tetraploids are much larger than fast in any fossil Ginkgoales (ref. ${ }^{71}$ : Table S1; ref. ${ }^{72}$ : Table S1; ref. ${ }^{26}$ ). The exception represent two samples of Jurrasic Sphenobaiera, whose pore size $(\sim 52.7 \mu \mathrm{m})^{72}$ is comparable to the pore length found in Ginkgo triploids and tetraploids (cf. Fig. S4). Although this finding suggests existence of polyploidy deep in the 
Ginkgoales history, the molecular evidence yet shows this was likely not the case of the extant Ginkgo lineage (accepting the critics ${ }^{22}$ of the previous evidence in the Ginkgo genomic data ${ }^{21}$ ). The reported polyploidy in Ginkgo therefore most probably represent an absolute evolutionary novelty in Ginkgo. The availability of multiple polyploid Ginkgo trees increases the chance some will be fertile and able to be further bred. If so, we may seriously start to think about breeding a new polyploid species of Ginkgo and to substantially accelerate the modern diversification of this fossil plant lineage.

\section{Acknowledgements}

We thank Vladimír Ožana, Jana Blažičková, Josef Hahnl, Manfred Bindewald, Oldřich Chadima, Jan Sláma, and other Ginkgo fans and growers listed in Table S1 for providing leaves of their Ginkgo plants and Manfred Bindewald and Roman Hobza for commenting on early versions of the paper. This work was supported by the Czech Science Foundation (grant GAČR P505 1430313S)

\section{Author's contribution}

P.S. managed the project and wrote the paper with comments from P.B.; P.S., O.K., and P.V. sampled plants and prepared figures; H.D., M.D., L.P., L.O., K.R., and P.H. provided Ginkgo samples; L.H. conducted flow cytometry and stomatal measurement with the assistance of K.V.

\section{Author details}

'Department of Botany and Zoology, Masaryk University, Koltlářská 2, CZ-61137 Brno, Czech Republic. ${ }^{2}$ Herrenkamper Gärten, Herrenkamp 1, DE-27254 Siedenburg, Germany. ${ }^{3}$ Department of Genetics and Plant Breeding, Slovak University of Agriculture in Nitra, Tr. A. Hlinku 2, 94976 Nitra, Slovakia. ${ }^{4}$ Slovak University of Agriculture in Nitra, Faculty of Horticulture and Landscape Engineering, Dunajská 16, 94911 Nitra, Slovakia. ${ }^{5}$ Botanical Garden of Eötvös University, Illés utca 25, Budapest, Hungary

\section{Conflict of interest}

The authors declare that they have no conflict of interest.

Supplementary Information accompanies this paper at https://doi.org/ 10.1038/s41438-018-0055-9.

Received: 9 January 2018 Revised: 7 May 2018 Accepted: 21 May 2018 Published online: 01 October 2018

\section{References}

1. Zhou, Z. An overview of fossil Ginkgoales. Palaeoworld 18, 1-22 (2009).

2. Taylor, T. S., Taylor, E. L. \& Krings, M. Paleobotany (Academic Press, Singapore, 2009).

3. Tralau, H. The phytogeographic evolution of the genus Ginkgo L. Bot. Notiser 120, 409-422 (1967)

4. Bego, B. M. B. Nature's miracle. Ginkgo biloba L. 1771. 1, 2 (2011).

5. Crane, P. R. Ginkgo: The Tree that Time Forgot (Yale University Press, New Haven, CT, USA and London, UK, 2013).

6. Gong, W., Chen, C., Dobes, C., Fu, C. X. \& Koch, M. A. Phylogeography of a living fossil: Pleistocene glaciations forced Ginkgo biloba L. (Ginkgoaceae) into two refuge areas in China with limited subsequent postglacial expansion. Mol. Phyl. Evol. 48, 1095-1105 (2008).

7. Santamour, F. S., He, S. \& McArdle, A. J. Checklist of cultivated Ginkgo. J. Arboric. 9, 88-92 (1983)

8. Dieck, H. Ginkgo: Das Sortenbuch (Herrenkamper Gärten, Siedenburg, Germany, 2010)

9. Levin, D. A. The Role of Chromosomal Change in Plant Evolution (Oxford University Press, Oxford, UK, 2002).
10. Otto, S. P. The evolutionary consequences of polyploidy. Cell 131, 452-462 (2007).

11. Van de Peer, Y., Mizrachi, E. \& Marchal, K. The evolutionary significance of polyploidy. Nat. Rev. Genet. 18, 411-424 (2017).

12. Fawcett, J. A., Maere, S. \& Van de Peer, Y. Plants with double genomes might have had a better chance to survive the Cretaceous-Tertiary extinction event. Proc. Natl. Acad. Sci. USA 106, 5737-5742 (2009).

13. Soltis, D. E. et al. Polyploidy and angiosperm diversification. Am. J. Bot. 96, 336-348 (2009).

14. Vanneste, K., Baele, G., Maere, S. \& Van de Peer, Y. Analysis of 41 plant genomes supports a wave of successful genome duplications in association with the Cretaceous-Paleogene boundary. Genome Res. 24, 1334-1347 (2014).

15. Soltis, P. S. \& Soltis, D. E. Ancient WGD events as drivers of key innovations in angiosperms. Curr. Opin. Plant Biol. 30, 159-165 (2016).

16. Sax, K. \& Sax, H. J. Chromosome number and morphology in conifers. J. Arnold Arbor. 14, 356-375 (1933).

17. Khoshoo, T. N. Polyploidy in gymnosperms. Evolution 13, 24-39 (1959).

18. Ahuja, M. R. Polyploidy in gymnosperms: revisited. Silvae Genet. 54, 59-69 (2005).

19. Leitch, A. R. \& Leitch, I. J. Ecological and genetic factors linked to contrasting genome dynamics in seed plants. New Phytol. 194, 629-646 (2012).

20. Husband, B. C., Baldwin, S. J. \& Suda, J. in Plant Genome Diversity, Vol. 2. (eds Leitch, I. J., Greilhuber, J., Dolezel, J. \& Wendel, J.) pp 255-276 (Springer, Vienna, Austria, 2013).

21. Li, Z. et al. Early genome duplications in conifers and other seed plants. Sci. Adv. 1, e1501084 (2015)

22. Roodt, D. et al. Evidence for an ancient whole genome duplication in the cycad lineage. PLOS ONE 12, e0184454 (2017).

23. Tulecke, W. R. A tissue derived from the pollen of Ginkgo biloba. Science $\mathbf{1 1 7}$ 599-600 (1953).

24. Trémouillaux-Guiller, J., Laurain, D. \& Chénieux, J. C. in In Vitro Haploid Production in Higher Plants, Vol. 3. Important Selected Plants (eds Mohan, J., Sopory, S. K. \& Veilleux, R. E.) 277-295 (Springer, Dordrecht, Neederlands, 1996).

25. Sun, Y. et al. Effect of colchicine treatment on the microtubule cytoskeleton and total protein during microsporogenesis in Ginkgo biloba L. Pak. J. Bot. 47, 159-170 (2015).

26. Šmarda, P. et al. Polyploidy in a "living fossil" Ginkgo biloba. New Phytol. 212, 11-14 (2016)

27. Ražná, K. \& Hrubík, P. Ginkgo dvojlaločné (Ginkgo biloba L.)—genomická štúdia a kultúrne rozšrrenie na Slovensku [Maidenhair tree (Ginkgo biloba L.)—Genomic Study and Cultural Distribution in Slovakia] (Slovenská polinohospodárská univerzita v Nitre, Nitra, Slovakia, 2016).

28. Doležel, J., Sgorbati, S. \& Lucretti, S. Comparison of three DNA fluorochromes for flow cytometric estimation of nuclear DNA content estimation in plants. Physiol. Plant 85, 625-631 (1992).

29. Veselý, P., Bureš, P., Šmarda, P. \& Pavlíček, T. Genome size and DNA base composition of geophytes: the mirror of phenology and ecology? Ann. Bot. 109, 65-75 (2012).

30. Otto, F. DAPI staining of fixed cells for high-resolution flow cytometry of nuclear DNA. Methods Cell Biol. 33, 105-110 (1990).

31. Masterson, J. Stomatal size in fossil plants: evidence for polyploidy in majority of angiosperms. Science 264, 421-424 (1994).

32. Hodgson, J. G. et al. Stomatal vs. genome size in angiosperms: the somatic tail wagging the genomic dog? Ann. Bot. 105, 573-584 (2010).

33. Zhao, Y., Paule, J., Fu, C. \& Koch, M. A. Out of China: distribution history of Ginkgo biloba L. Taxon 59, 495-504 (2010).

34. Cao, F. S. An Illustrated Monograph of Ginkgo biloba L. Cultivars in China (Science Press, Bejing, China, 2011).

35. Isakov, Y. N., Butorina, A. K. \& Muraya, L. S. Discovery of spontaneous haploids in Pinus silvestris and the prospects of their using in forest genetics and selection. Genetika 17, 701-707 (1981).

36. Andersen, S. B. in Haploids in Crop Improvement (eds Palmer, C. E., Keller, W. A \& Kasha, K. J.) pp 243-257 (Springer, Berlin, Heidelberg, Germany, 2005).

37. Dunwell, J. M. Haploids in flowering plants: origins and exploitation. Plant Biotechnol. J. 8, 377-424 (2010).

38. Chen, R. Y., Song, W. Q. \& Li, X. L. in Proceedings of Sino-Japan Symposium on Plant Chromosome Research (ed Hong, D.) pp 381-386 (Organizing Committee of the Symposium, Bejing, China, 1989).

39. Lan, T. et al. Microdissection and painting of the W chromosome in Ginkgo biloba showed different labelling patterns. Bot. Stud. 49, 33-37 (2008). 
40. Coder, K. D. Selected Ginkgo Forms and Cultivars (University of Georgia, Georgia, USA, 2003).

41. Murovec, J. \& Bohanec, B. in Plant Breeding (ed. Abdurakhmonov, I.) pp 87-106 (inTech, Rijeka, Croatia, 2012).

42. Kasha, K. J. in Haploids in Crop Improvement II (eds Palmer, C. E., Keller, W. A. \& Kasha, K. J.) pp 123-152 (Springer, Heidelberg, Germany, 2005).

43. Kimber, G. \& Riley, R. Haploid angiosperms. Bot. Rev. 29, 480-531 (1963).

44. Cook, M. T. Polyembryony in Ginkgo. Bot. Gaz. 36, 142 (1903).

45. Illies, Z. M. Auftreten haploider Keimlinge bei Picea abies. Naturwissenschaften 51, 442 (1964).

46. Dwivedi, S. L. et al. Haploids: constraints and opportunities in plant breeding. Biotechnol. Adv. 33, 812-829 (2015).

47. Neale, D. B. et al. Decoding the massive genome of loblolly pine using haploid DNA and novel assembly strategies. Genome Biol. 15, 1-13 (2014).

48. Harkess, A. et al. The asparagus genome shed light on the origin and evolution of a young Y chromosome. Nat. Commun. 18, 1279 (2017).

49. Guan, R. et al. Draft genome of the living fossil Ginkgo biloba. Gigascience 5, 49 (2016).

50. Abraham, A. \& Mathew, P. M. Cytology of Encephalartos hildebrandtii A. Br. et Bouche. Ann. Bot. 30, 239-241 (1966).

51. Ramsey, J. \& Schemske, D. W. Pathways, mechanisms, and rates of polyploid formation in flowering plants. Ann. Rev. Ecol. Syst. 29, 467-501 (1998).

52. Johnsson, $\mathrm{H}$. Observations on induced polyploidy in some conifers. Silvae Genet. 24, 62-68 (1975).

53. Christiansen, H. A tetraploid Larix decidua Miller. Det. K. Dan. Vidensk. Selsk. Biol. Medd. 18, 1-8 (1950).

54. Libby, W. J., Stettler, R. F. \& Seitz, F. W. Forest genetics and forest tree breeding. Ann. Rev. Genet. 3, 469-494 (1969).

55. Nagata, T., Hasebe, M., Toriba, T., Taneda, H., \& Crane, P. R. Sex conversion in Ginkgo biloba (Ginkgoaceae). J. Jpn. Bot. 91(Suppl.), 120-127 (2016).

56. Ming, R., Bendahmane, S. \& Renner, S. S. Sex chromosomes in land plants. Ann. Rev. Plant Biol. 62, 485-514 (2011).

57. Charlesworth, D. Plant sex chromosome evolution. J. Exp. Bot. 64, 405-420 (2013).
58. Akagi, T., Henry, I. M., Tao, R. \& Comai, L. A Y-chromosome-encoded small RNA acts as sex determinant in persimmons. Science 346, 646-650 (2014).

59. Osborn, T. C. et al. Understanding mechanisms of novel gene expression in polyploids. Trends Genet. 19, 141-147 (2003).

60. Jackson, S. \& Chen, Z. J. Genomic and expression plasticity of polyploidy. Curr. Opin. Plant. Biol. 13, 153-159 (2010).

61. Westergaard, $M$. The mechanism of sex determination in dioecious flowering plants. Adv. Genet. 9, 217-281 (1958).

62. Richards, A. J. Plant Breeding Systems (Chapman \& Hall, London, UK, 1997).

63. Pannell, J. R., Obbard, D. J. \& Buggs, R. J. A. Polyploidy and the sexual system: what can we learn from Mercurialis annua. Biol. J. Linn. Soc. 82, 547-560 (2004).

64. Russell, J. R. W. \& Pannell, J. R. Sex determination in dioecious Mercurialis annua and its close diploid and polyploid relatives. Heredity 114, 262-271 (2015).

65. Cavalier-Smith, T. Economy, speed and size matter: evolutionary forces driving nuclear genome miniaturization and expansion. Ann. Bot. 95, 147-175 (2005).

66. Stebbins, G. L. Variation and Evolution of Plants (Columbia University Press, New York, USA, 1950).

67. Beaulieu, J. M., Leitch, I. J., Patel, S., Pendharkar, A. \& Knight, C. A. Genome size is a strong predictor of cell size and stomatal density in angiosperms. New Phytol. 179, 975-986 (2008).

68. Stebbins, G. L. Chromosomal Evolution in Higher Plants (Edward Arnold, London, UK, 1971).

69. Beaulieu, J. M. et al. Correlated evolution of genome size and seed mass. New Phytol. 173, 422-437 (2007).

70. Knight, C. A. \& Beaulieu, J. M. Genome size scaling through phenotype space. Ann. Bot. 101, 759-766 (2008).

71. Lomax, B. H., Woodward, F. I., Leitch, I. J., Knight, C. A. \& Lake, J. A. Genome size as a predictor of guard cell length in Arabidopsis thaliana is independent of environmental conditions. New Phytol. 181, 311-314 (2009).

72. McElwain, J. C. \& Steinthorsdottir, M. Paleoecology, ploidy, paleoatmospheric composition, and developmental biology: a review of multiple uses of fossil stomata. Plant Physiol. 174, 650-664 (2017). 